\title{
Kinetics and Mechanism of the Oxidation of $\alpha$-Hydroxy Carboxylic Acids by Bromine
}

\author{
KALYAN K. BANERJI \\ Department of Chemistry, University of Jodhpur, Jodhpur, India \\ (Z. Naturfor:ch. 28 b, 450-453 [1973]; reccived November 8, 1972/March 19, 1973) \\ Hydroxy acid, oxidation, bromine
}

\begin{abstract}
The oxidation of glycollic, lactic, $\alpha$-hydroxybutyric, and 2-phenyllactic acids by aqueous bromine has been studied. The reaction is of first order with respect to the oxidant and the anion of the hydroxy acid respectively. The active oxidising species is molecular bromine. The oxidation of $\alpha, \alpha$-dideuterioglycollic acid indicated a kinetic isotope effect, $k_{\mathrm{H}} / k_{\mathrm{D}}=4.62$ at $25{ }^{\circ} \mathrm{C}$. The reaction does not show any appreciable solvent isotope effect. The activation parameters are evaluated. $\Lambda$ probable mechanism has been suggested.
\end{abstract}

The main features of the oxidation of alcohols by bromine is now well established ${ }^{1}$ and is known to involve a rate-determining transfer of a hydride ion ${ }^{2}$. There seems to be however, no report on the oxidation of $\alpha$-hydroxy acids by bromine except of some preliminary investigations by PURKayastha ${ }^{3}$ back in 1929. Hence it was considered worthwhile to reinvestigate the reaction. The present communication reports the kinetics of the oxidation of glycollic, lactic, $\alpha$-hydroxybutyric, and 2-phenyllactic acid by aqueous bromine.

\section{Results and Discussion}

\section{Product analysis}

Oxidation of excess of the hydroxy acids by aqueous bromine leads only to oxidation products, no substitution was detected. The main products are aldehydes as confirmed by the formation of their 2,4-dinitrophenylhydrazones.

Estimation of formaldehyde formed by the oxidation of glycollic acid (Table I) indicated the following overall reaction.

Table I. Estimation of formaldehyde produced by the oxidation of glycollic acid.

\begin{tabular}{llccc}
\hline [GA] 0.05 & \multicolumn{4}{c}{ pH 3.50} \\
\hline $10^{3}\left[\mathrm{Br}_{2}\right] \mathrm{M}$ & 2.0 & 4.0 & 8.0 & 10 \\
$10^{3}[\mathrm{HCOH}] \mathrm{M}$ & 1.9 & 4.0 & 7.8 & 9.9 \\
\hline
\end{tabular}

Requests for reprints should be sent to Dr. K. K. Banerji, The Dyson Perrins Laboratory, South Parks Road, Oxford, OX1 3QY, England.

$$
\begin{aligned}
& \mathrm{CH}_{2} \mathrm{OHCOOH}+\mathrm{Br}_{2} \rightarrow \mathrm{HCHO}+\mathrm{CO}_{2}+ \\
& +2 \mathrm{HBr}
\end{aligned}
$$

Ratc laws

When the concentration of the hydroxy acid is in excess the rate of disappearence of bromine follows first order rate laws. The first rate constants were obtained from the plots of $\log$ [oxidant] against time.

In aqueous buffered solution, the rate of the oxidation is proportional to the concentration of the anion of the hydroxy acid. As the hydroxy acids studied here gave similar results, the data of glycollic acid (GA) only are reproduced (Table II). The

Table 1I. Substrate dependence of the reaction rate.

\begin{tabular}{lclccc}
\hline pH 3.85 & \multicolumn{1}{c}{ Temp. $\left[25^{\circ} \mathrm{C}\right]$} & \multicolumn{3}{c}{$\mathrm{Br}_{2}[0.001 \mathrm{M}]$} \\
\hline$\left[\mathrm{GA}^{-}\right] .10^{-2} \mathrm{M}$ & 2.0 & 4.0 & 6.0 & 8.0 & 10 \\
$10^{8} k_{1}, s^{-1}$ & 4.60 & 9.10 & 14.0 & 18.5 & 23.2 \\
$10^{6} k_{1} /\left[\mathrm{GA}^{-}\right]$ & 2.30 & 2.27 & 2.33 & 2.31 & 2.32 \\
\hline
\end{tabular}

second order rate constants reported herein were obtained from the relation $k_{2}=k_{1} /$ [hydroxy acid anion], where $k_{1}$ is the observed pseudo-first-order rate constant. The concentration of the anions were calculated by using the known $\mathrm{pK}$ values of the hydroxy acids.

\section{Nature of the oxidising specics}

The rate law for the reaction can be written as follows:

$d x / d t=k$ [hydroxy acid anions] [oxidant]

In aqueous buffered solution, the probable oxidising species are $\mathrm{Br}_{2}, \mathrm{HOBr}$ and $\mathrm{Br}_{3}{ }^{-}$. If we con- 
sider all these three, the meaning of $k$ in Eqn (2) becomes (at constant [hydroxy acid anion]) $)^{4}$,

$k=k_{\mathrm{Br}_{2}} \mathrm{~K}_{3} /\left(\mathrm{K}_{3}+\left[\mathrm{Br}_{3}^{-}\right]\right)+k_{\mathrm{Br}_{3}}-\left[\mathrm{Br}^{-}\right] /$

$\left(\mathrm{K}_{3}+\left[\mathrm{Br}^{-}\right]\right)+k_{\mathrm{HOBr}_{3}} \mathrm{~K}_{3} \mathrm{~K}_{\mathrm{h}} /\left(\mathrm{K}_{3}+\left[\mathrm{Br}^{-}\right]\right)$

$\left[\mathrm{Br}^{-}\right]\left[\mathrm{H}^{+}\right]$

where $K_{3}$ is the dissociation constant of the tribromide ion, $K_{h}$ is the hydrolysis constant of bromine, and use is made of the fact that under the experimental conditions:

$[\mathrm{HOBr}] \ll\left[\mathrm{Br}_{2}\right]$

The oxidation of glycollic acid at $\mathrm{pH} 3.85$ was studied with increasing concentration of sodium bromide $(0.035-0.35 \mathrm{M})$. A plot of $k_{2}$ against $\left(1 /\left(\mathrm{K}_{3}+\left[\mathrm{Br}^{-}\right]\right)\right.$gives a straight line passing through origin (Fig. 1), $\mathrm{K}_{3}$ was taken ${ }^{5}$ as 0.0625 at $25^{\circ} \mathrm{C}$. The

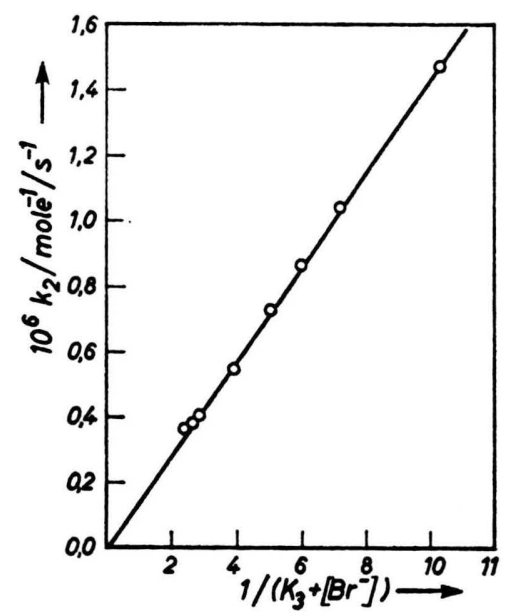

Fig. 1. Effect of bromide ions on the oxidation of glycollic acid $(0.02 \mathrm{M})$ by bromine $(0.002 \mathrm{M})$ at $25^{\circ} \mathrm{C}$, $\mathrm{pH}=3.85, \mu=1.0 \mathrm{M}$.

fact that a straight line is obtained shows that the contribution of third number of Eqn (3) is negligible. Furthermore this line passes through origin and shows that as $\left[\mathrm{Br}^{-}\right] \rightarrow \infty$ and therefore $\left[\mathrm{Br}_{3}{ }^{-}\right] \rightarrow$ [oxidant], $k \rightarrow 0$ and hence $k_{\mathrm{Br}_{3}-} \ll k_{\mathbf{B r}_{2}}$.

In view of the relation (4) the findings of the above experiments yield no information about $k_{\text {HOBr}}$. However, when log [oxidant] was plotted against time, for a reaction which initially contained pure hypobromous acid as an oxidizing agent, the curve started very flat and becomes steeper and steeper as the reaction proceeded. This may be because the reduction of hypobromous acid produces bromide ions, which react with unchanged hypo- bromous acid to give bromine, which in turn rapidly attacks the organic substrate.

This confirms that in bromine water, the active oxidizing species is molecular bromine. Similar conclusions were drawn by Pearlmutter-Hay$M \Lambda N^{4,6}$ in the oxidation of glucose and ethanol.

\section{Effect of $\mathrm{pH}$}

The rate of the oxidation of the hydroxy acids were studied in the $\mathrm{pH}$ range of $0.5-6.0$. The rate of oxidation is not much sensitive to $\mathrm{pH}$ at very low $\mathrm{pH}$ values but in moderate $\mathrm{pH}$ range, the rate increases sharply (Fig. 2). It can be seen that the $\mathrm{pH}$

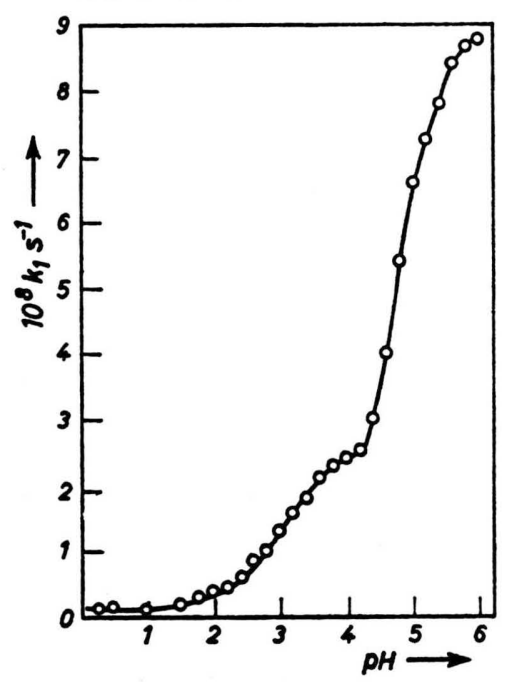

Fig. 2. $\mathrm{pH}$ Dependence of the rate of oxidation of glycollic acid $(0.02 \mathrm{M})$ by bromine $(0.002 \mathrm{M})$ at $25^{\circ} \mathrm{C}$, $\mu=1.0 \mathrm{M}$.

profile of the oxidation is quite parallel to the neutralization curve of the acid. This confirms the earlier observation that the active reacting species is the anion of the $\alpha$-hydroxy acid. Similar observations were made by PURKAY STH $^{3}$ also.

Grover and Mehrotrs ${ }^{7}$, on the basis of similar increase in the rate of the oxidation of glucose with increasing $\mathrm{pH}$, suggested hypobromous acid as the active oxidising species. However, experiments described in the earlier section show this view to be crroneous. The variation in the rate with $\mathrm{pH}$, may well be due to the participation of anion of glucose at higher $\mathrm{pH}$.

\section{Kinetic isotope effect}

The oxidation of ethanol ${ }^{8}$ and benzyl alcohol ${ }^{2}$ by bromine involves $\alpha-\mathrm{C}-\mathrm{H}$ cleavage as shown by 
the presence of considerable kinetic isotope effect $\left(\left(k_{\mathbf{H}} / k_{\mathbf{D}} \sim 4\right)\right.$. The oxidation of $\alpha, \alpha$-dideuterioglycollic acid $\left(\mathrm{CD}_{2} \mathrm{OH} \cdot \mathrm{COOH}\right)$ by bromine was studied to determine the kinetic isotope effect. The rate constants for the oxidation of the deuterio and ordinary glycollic acid, at $\mathrm{pH} 3.83$ and $25^{\circ} \mathrm{C}$, are $10^{7} k_{2}=5.0$ and $23.1 \mathrm{l} / \mathrm{mole} / \mathrm{sec}$ respectively, and the kinetic isotope effect, $k_{\mathrm{H}} / k_{\mathrm{D}}=4.62$. This confirms that the oxidation of the hydroxy acid also involves the rupture of $\alpha-\mathrm{C}-\mathrm{H}$ bond.

\section{Solvent isotope effect}

The oxidation of half-neutralized glycollic acid $(0.05 \mathrm{M})$ was studied in deuterium oxide and in water, in the absence of added buffers. The rate constants at $25^{\circ} \mathrm{C}$ are $10^{6} k_{2}=2.31$ and 2.10 $\mathrm{l} / \mathrm{mole} / \mathrm{sec}$ respectively. The solvent isotope effect, $k\left(\mathrm{H}_{2} \mathrm{O}\right) / k\left(\mathrm{D}_{2} \mathrm{O}\right)=1.10$, does not differ significantly from unity and indicates that the rupture of $\mathrm{O}-\mathrm{H}$ bond is not occurring in the rate-determining step.

\section{Oxidation of methoxyacetic acid}

Several oxidations are known to proceed through formation of an ester intermediate. Formation of a hypobromite ester as an intermediate in bromine oxidation is a distinct possibility. To test this, the methyl ether of glycollic acid was oxidized.The rate constant for the oxidation of a half neutralized solution of methoxyacetic acid $(0.05 \mathrm{M})$ by bromine $(0.005 \mathrm{M})$ at $25^{\circ} \mathrm{C}$, is $k_{2}=1,5310^{-} \mathrm{c} \mathrm{l} / \mathrm{mole} / \mathrm{sec}$.

\section{Effect of temperature}

The glycollic, lactic, $\alpha$-hydroxybutyric, and 2-phenyllactic acids by bromine were studied at different temperatures (Table III). In order to get compara-

Table III. Temperature dependence of the reaction rate.

\begin{tabular}{lcccccc}
\hline Acid & \multicolumn{5}{c}{$10^{6} k_{2}$} & \multicolumn{1}{c}{$\mathrm{mole}^{-1} / \mathrm{sec}^{-1}$} \\
& Temp $\left[{ }^{\circ} \mathrm{C}\right]$ & 25 & 30 & 35 & 40 & 45 \\
\hline Glycollic & 2.31 & 3.80 & 6.03 & 9.55 & 15.1 \\
Lactic & 41.0 & 60.0 & 87.1 & 124 & 174 \\
x-Hydroxybutyric & 70.0 & 97.6 & 133 & 180 & 240 \\
2-Phenyllactic & 89.3 & 123 & 167 & 224 & 300 \\
\hline
\end{tabular}

ble rates, this set of experiments were conducted at $\mathrm{pH}$ values which are equal to the $\mathrm{pK}$ values of the hydroxy acids. The activation parameters were also evaluated (Table IV). The error limits in the values of $\Delta H^{\ddagger}, \Delta S^{\ddagger}$, and $\Delta F^{\mp}$ are approx. $\pm 1.5 \mathrm{kcal} / \mathrm{mole}$, $\pm 2.0 \mathrm{cal} / \mathrm{mole} / \mathrm{K}$, and $\pm 2.0 \mathrm{kcal} / \mathrm{mole}$ respectively.
Table IV. Activation parameters.

\begin{tabular}{lccc}
\hline Acid & $\begin{array}{c}\Delta H^{\neq} \\
\mathrm{kcal} / \mathrm{mole}\end{array}$ & $\begin{array}{c}\Delta S^{\neq} \\
\mathrm{kcal} / \mathrm{mole} / \mathrm{K}\end{array}$ & $\begin{array}{c}\Delta F_{298} \\
\mathrm{kcal} / \mathrm{mole}\end{array}$ \\
\hline Glycollic & 17.3 & 26.3 & 24.1 \\
Lactic & 13.7 & 28.8 & 22.3 \\
Q-Hydroxybutyric & 11.6 & 39.3 & 23.3 \\
2-Phenyllactic & 11.4 & 39.5 & 23.2 \\
\hline
\end{tabular}

The formation of organic hypobromite is unlikely in view of the almost equal ease of the oxidation of glycollic acid and its methyl ether . The above results show that the oxidation of $\alpha$ hydroxy acids is similar to that of alcohols. The oxidation of alcohols by bromine involves removal of the hydride ion from the carbinol carbon ${ }^{10}$. However, the oxidation of $\alpha$-hydroxy acid involves decarboxylation also this may be either simultaneous with the hydride ion removal or be a fast reaction afterwards. No $\alpha$-keto acid is detected as product and hence its formation as a discrete intermediate is unlikely. The following mechanism may then be proposed. The decarboxylation is shown as a rapid reaction following the rate-determining step but it may well be synchronous with the same. The intermediate (A) is likely to be highly unstable and should rearrange itself almost instantaneously to an aldehyde.

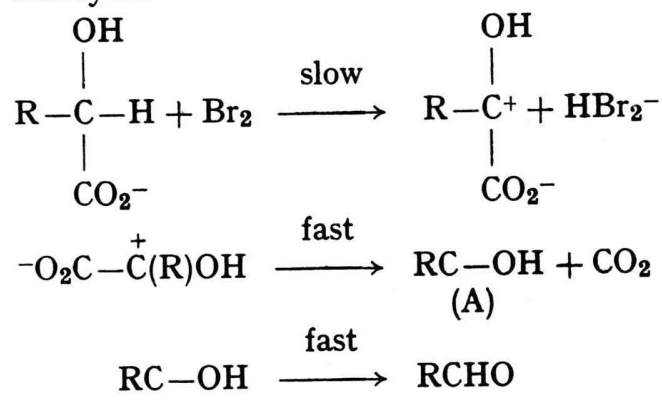

\section{Experimental}

The hydroxy acids were commercial products and were purified by the usual methods. Bromine (AnalR, B.D.H.) was used without purification. All other reagents used were of analytical grade.

$\alpha \alpha$,-Dideuteriogylcollic acid $\left(\mathrm{CD}_{2} \mathrm{OH} \cdot \mathrm{COOH}\right)$ was prepared by the method of KEMP and WATERS ${ }^{11}$ Its NMR spectrum showed the isotopic purity to be $97.7 \%$. Methoxyacetic acid was prepared by the methylation of glycollic acid by dimethyl sulphate ${ }^{12}$.

\section{Product analysis}

The reaction mixtures containing excess of glycollic acid and varying proportion of bromine were left overnight to ensure complete reduction of bromine. 
The amounts of formaldehyde was estimated colourimetrically by the chromotropic acid method ${ }^{13}$.

\section{Kinetic measurements}

Preliminary experiments showed that the reaction is not affected by diffuse day light and hence experiments were carried out in ordinary light. The $\mathrm{pH}$ was adjusted using phosphate and acetate buffers, very low $\mathrm{pH}$ were obtained by the use of perchloric acid. The $\mathrm{pH}$ values are correct to \pm 0.01 . The reaction is not appreciably affected by either the nature of the buffer or the ionic strength. For the reaction in deuterium oxide, $\mathrm{pH}$ was adjusted by addition of $\mathrm{NaOD}$ to glycollic acid.

The reactions were carried out under pseudo-firstorder conditions by keeping a large excess of the hydroxy acid $(\sim 10)$ over bromine. The reactions were followed spectrophotometrically at $398 \mathrm{~nm}$. The rate constants reported are mean of multiple runs and are reproducible within $\pm 4 \%$.

\section{Oxidation by hypobromous acid}

Hypobromous acid was prepared by mixing yellow mercuric oxide with bromine water, decanting and distilling in vacuo ${ }^{14}$. The oxidations were carried out in presence of a large excess of hydoxy acid and were fellowod iodometrically.
Some experimental part and the preparation of the manuscript were completed during my stay at the Dyson Perrins Laboratory, Oxford, and I thank the authorities of the laboratory for the hospitality.

1 I. R. L. BARKER, Chem. and Ind. 1964, 1936.

2 P. Aukett and I. R. L. Barker, J.C.S. Perkin II [London] 1972, 568.

3 R.M. Purkasthaya, J. Indian chem. Soc. 6, 375, 385 [1929].

4 B. Pearlmutter-Hayman and A. Persky, J. Amer. chem. Soc. 82, 276 [1960].

5 G. Jones and S. Baeckstorm, J. Amer. chem. Soc. 56, 1517 [1934].

6 B. Pearlmutter-Hayman and Y. Weissmann, J. Amer. chem. Soc. 84, 2323 [1962].

7 K.C. Grover and R.C. Mehrotra, Z. physik. Chem. 14, 345 [1958]; 18, 401 [1958].

${ }^{8}$ L. Kaplan, J. Amer. chem. Soc. 80, 2639 [1958].

9 R. Brownell, A. Leo, Y.W. Chang, and F.H. Westheimer, J. Amer. chem. Soc. 82, 406 [1960].

$10 \mathrm{~K}$. K. BANERJI, Indian J. Chem., in press.

11 T. J. KemP and W. A. WAters, J. chem. Soc. [London] 1964, 1194.

12 W. Reeve and I. Christoffel, J. Amer. chem. Soc. 72, 1480 [1950].

13 J. Mitchell, Jr., “Organic Analysis", p.228, Vol. I, Interscience Publishers, New York 1953.

14 Y. Knoller and B. Pearlmutter-Hayman, J. Amer. chem. Soc. 77, 3212 [1955]. 